\title{
The Prevalence of Four Types of Childhood Maltreatment in Denmark
}

\author{
Mogens N. Christoffersen ${ }^{\mathrm{a}}$, Cherie Armour ${ }^{\mathrm{b}, *}$, Mathias Lasgaard ${ }^{\mathrm{c}}$, Tonny E. Andersen ${ }^{\mathrm{c}}$ and Ask \\ Elklit $^{\mathrm{c}}$
}

${ }^{a}$ The Danish National Centre for Social Research, Denmark

${ }^{b}$ Department of Psychology, University of Ulster, Coleraine, Northern Ireland

${ }^{c}$ National Centre for Psychotraumatology, University of Southern Denmark, Campusvej 55, DK-5230 Odense M, Denmark

\begin{abstract}
Objectives: To estimate the prevalence of four types of childhood maltreatment in Denmark while taking into considerations how each of the types of maltreatment vary as a function of gender or child-protection status.

Methods: Data were collected from a Danish national study conducted by The Danish National Centre for Social Research in 2008 and 2009. The study used a stratified random probability sample of young people aged 24 years. A sample of 4718 young adults were randomly selected by Statistics Denmark using the total birth cohort of all children born in 1984 . The response rate was $63 \%$ leaving a total effective sample size of 2980 . A structured residential or telephone interview enquired about a range of respondents maltreatment experiences.

Results: Maltreatment is experienced by a significant proportion of Danish children. The reported prevalence rates were; physical neglect (3.0\%), emotional abuse (5.2\%), physical abuse (5.4\%) and sexual abuse (3.4\%). All trauma types were experienced by a greater percentage of females compared to males with the exception of physical abuse and all trauma types were experienced by a greater percentage of children given child-protection status.

Conclusions: Female children and children who are given child protection status are those most at risk for experiencing maltreatment in Denmark. However, variability in prevalence rates of maltreatment across studies is problematic. Methodological variations and variation in abuse definitions may be partly attributable.
\end{abstract}

Keywords: Emotional Abuse, Epidemiology, Physical Abuse, Physical Neglect, Sexual Abuse.

\section{INTRODUCTION}

Childhood maltreatment is associated with a range of mental and physical health consequences. These consequences are apparent in childhood and often continue for many years into adulthood. Individuals who have been sexually or physically abused are more likely to experience serious health problems compared to their non-abused counterparts $[1,2]$. Within the research literature there is a general consensus regarding the categorisation of types of childhood maltreatment. The Fourth US National Incidence Study of Child Abuse and Neglect (NIS-4) [3] identified four types of childhood maltreatment; physical abuse, sexual abuse, emotional abuse, and neglect. The current study will assess the prevalence of all four. Physical abuse is defined as an inflicted act causing physical injury to the child or exposing the child to risk of physical injury. Sexual abuse refers to sexually motivated behaviours between the child and an older person involving the child or sexual exploitation of the child, often involving bodily contact, but not necessarily. Emotional abuse is defined as caregiver behaviours that con-

*Address correspondence to this author at the Department of Psychology, University of Ulster, Coleraine, BT52 1SA, Northern Ireland;

Tel: 0044 (0)2870123374; E-mail: c.armour1@ulster.ac.uk vey to the children that they are worthless, flawed, unloved, unwanted, endangered, or only of value in meeting another's needs. Finally, neglect is defined as failing to give the child the care needed according to the child's age and development, for instance having too much responsibility, failure to provide safe health care, unsafe household conditions, inadequate clothing and nutrition, and a lack of supervision $[3,4]$.

\section{PREVALENCE OF MALTREATMENT}

The existence of childhood maltreatment is a major concern worldwide. Information with regards to the number of children who are maltreated is predominantly based on the number of cases which are reported to the authorities or on studies which have focused on single types of maltreatment. However, it is estimated that only a limited number of all cases of maltreatment are reported to the authorities [5]. More precise knowledge about the prevalence of childhood maltreatment can be achieved by conducting studies which utilize large-scale nationally representative samples. To date, only a limited number of nationally representative studies in relation to childhood maltreatment have been conducted. However, these studies have generally focused on specific types of maltreatment [6-12]. Furthermore, the reported prevalence rates often differ dramatically. For example, studies have reported the prevalence of physical abuse ranging 
from $4.5 \%$ to $47 \%[6,8]$. In relation to sexual abuse, studies have reported prevalence rates which range from $3 \%$ to $36 \%$ [13]. This could reflect sample specific social and cultural differences. However, it is also likely to reflect the use of different methodological procedures.

\section{METHODOLOGICAL ISSUES}

The varying prevalence rates of childhood maltreatment reported across epidemiological studies may be attributed to methodological differences. For example, studies using convenience samples have on occasion reported higher rates of maltreatment, which may be attributable to sample specific variations. In addition, the use of retrospective studies has several limitations. One such limitation being, the temporal proximity between the occurrence of the event and the event recall. For example, studies employing retrospective selfreports about maltreatment, which occurred decades ago, may not be as precise as studies using self-reports from adolescents where the events occurred more recently and thus may be easier to recall.

A further issue affecting prevalence rates refers to how maltreatment is defined. Indeed, the majority of the extant research has employed broad categories of maltreatment, albeit some studies have asked questions in relation to specific events. Unfortunately however, these questions have often been ambiguous with regards to whether or not they are actually assessing maltreatment per se. May-Chahal and Cawson [10] for instance, found that $16 \%$ of their participants qualified for the formal definition of sexual abuse (contact and non-contact abuse), but that only $6 \%$ considered themselves as abused. Furthermore, even studies enquiring about specific types of maltreatment often use different definitions of events. For example, although sexual abuse is often categorised as both contact and non-contact sexual abuse, there is still no clear cut definition as to what actually constitutes sexual abuse. This trend is also apparent in the definition of other types of childhood maltreatment. For example, physical abuse is often defined very broadly, i.e., being hit by the hand of anyone. However, some studies do attempt to differentiate between mild and severe physical abuse $[6,8]$. Even vaguer definitions exist across studies in relation to emotional abuse and neglect. Precise definitions of what constitutes particular types of abuse would be advantageous from both a research and clinical perspective. The former as it would facilitate more precise estimates of prevalence and the latter as it has been reported that when asking about an individual's abuse history, specific well-defined types of maltreatment, promote recognition rather than recall and thus reduces the subjective interpretations of whether a certain event was abuse or not [14].

A final issue relates to anonymity in data collecting methodologies. For example, in an interview situation, the interviewee may not wish to disclose the abuse due to social taboos and potential feelings of embarrassment and shame. A number of alternative interviewing procedures help to overcome the potential of underreporting, for example, telephone interviewing and Computer Assisted Personal Interviewing if the interview is conducted face to face [10]. However, it is also important to note that variations in reported prevalence rates may not be solely attributable to methodo- logical differences. Indeed, a recent cross-national study of maltreatment in four nations (Denmark, Iceland, Lithuania, Faeroe Islands), each employing the same methodological procedures, reported rather different prevalence rates [7]. For example, severe childhood neglect was reported as five times higher in the Faeroe Islands compared to Lithuania. Thus, the Elklit and Petersen study indicated that cultural differences may exist over and above the differences which can be attributed to methodological variation. Indeed, culture specific norms may influence whether or not you regard yourself as having been abused.

\section{GENDER DIFFERENCES IN CHILDHOOD MAL- TREATMENT}

Child maltreatment has devastating consequences for both males and females, however important gender differences exist. Females are reported as experiencing sexual abuse to a far greater extent than males. Furthermore, females seem to be victimized more often in family-related events whereas males are more often victimized in activities outside the family [7]. Studies have also reported that gender affects post-abuse adjustment and symptoms. Sexual abuse has been associated with gynaecological problems, headaches, arthritis, and breast cancer for women and thyroid disease for men [2]. Furthermore, Banyard, Williams, and Siegel [15], when comparing females and males who had experienced sexual abuse, found that females had more mental health symptoms than males. Unfortunately, there are only a limited number of gender studies, employing nonclinical samples, available in the extant literature. It is however, important to note that gender based estimates of abuse may be biased in that males may underreport sexual abuse and the consequences thereof, thus artificially increasing the gender differences [16].

\section{NATIONALLY REPRESENTATIVE STUDIES OF CHILD MALTREATMENT}

The majority of studies tend to focus on specific types of maltreatment, generally either sexual abuse or physical abuse. Only a limited number of studies have assessed emotional abuse and neglect. Notably, fewer studies assess various types of maltreatment using nationally representative samples. Thus, given that all types of maltreatment have long-term consequences there is a need for more precise large-scale epidemiological studies gathering information on heterogeneous maltreatment types.

\section{AIM OF THE PRESENT STUDY}

Childhood maltreatment has been highlighted as having profound aversive consequences on both physical and psychological health. These aversive consequences are apparent in childhood but persist for many years to come leading to adulthood illness and significant psychological distress, e.g., PTSD. Indeed, most studies focus on only one specific type of abuse, despite research which has emphasized that the target and effectiveness of interventions may vary depending on the type of maltreatment [2]. The current study aimed to conduct a detailed assessment of the prevalence of childhood maltreatment in Denmark. Using a similar approach as MayChahal and Cawson [10], the present study asked partici- 
pants questions regarding specific experiences of four types of maltreatment; physical abuse, sexual abuse, emotional abuse and physical neglect, a method less flawed by subjective interpretations of whether maltreatment has occurred or not. The current study also aims to assess whether the prevalence of childhood maltreatment varies as a function of gender or child care status.

\section{METHODS}

\section{Procedure}

Data were collected from a Danish national study conducted by The Danish National Centre for Social Research in 2008 and 2009. The study used a stratified random probability sample of young people aged 24 years. The study was founded by the Danish Research Council. A sample of 4718 young adults with Danish citizenship was randomly selected by Statistics Denmark using the total birth cohort of all children born in 1984 (excluding persons who had refused to participate in national research or were imprisoned). Participation in the study was entirely voluntary and the study was approved by the Danish Data Protection Agency. To increase the number of participants who had experienced childhood abuse and neglect, children who had been in child protection where over-sampled by stratifying the number of "child protection cases" versus "non child protection cases" (1/3:2/3). A child protection case was defined as a case where the council (according to the files of local social workers) had provided support for the child and the family or placement with a foster family due to concerns about the well-being and development of the child.

The data was collected using a structured interview, which were conducted as a telephone interview or as a residential interview when a telephone interview could not be obtained. The average duration of the interview was estimated at 43 minutes. The response format was pre-coded but with an option for respondents to add additional comments as necessary. The interview did not define abuse and neglect per se but asked respondents if they had experienced specific incidences which are characterised as abusive or neglectful. A letter sent prior to the data collection informed each participant about the nature of the research, the possibility of being interviewed in the home, and the procedures securing confidentiality. Persons, who did not respond to the letter, where contacted by telephone if possible, and then eventually contacted at their home address. A minimum of six contact attempts (conducted during different times at the day as well as on working days and during the weekend) was made to each non-responding participant. At least three of these attempts were made at the home address.

The interviewers where carefully trained by The Danish National Centre for Social Research prior to the data collection. The training included detailed oral information and standardized written instructions regarding the purpose and content of the study. Moreover, test trials were conducted to familiarize the interviewers with the questionnaire and the coding procedure. The study included several sensitive questions regarding sexual abuse and violence. Hence, participants, who were interviewed in their home, answered these questions using computer assisted personal interviewing, whereby respondents could enter their answers directly on to a laptop computer. This method has been validated in similar studies [10]. Moreover, all participants were given the opportunity to speak to an experienced psychologist, via a telephone help line, after completing the interview.

\section{Participants}

A total of 2980 interviews were achieved with a response rate of $63 \%$. The most common reasons for non participation were refusal to take part in the study $(21 \%)$, lack of contact $(13 \%)$, and illness or disability $(2 \%)$. To adjust for the oversampling of child protection cases the data have been weighted so that findings are representative of the total Danish population of young people aged 24 years.

The demographic characteristics of the total sample (weighted), the non child protection cases, and the child protection cases are summarized in Table $\mathbf{1}$.

\section{Measures}

Physical Neglect. Retrospective reports on neglect by parents or guardians were obtained utilizing seven singleitems that describes different experiences of physical neglect (aged <12; please see Table 2). The items asked whether respondents had experienced seven types of physical neglect and scores were rated on a two-point (yes/no) format.

Emotional Abuse. Retrospective reports on emotional abuse by parents or guardians were obtained utilizing singleitems that describes different experiences of emotional abuse (aged $<12$; please see Table 3). The items asked whether respondents had experienced six types of emotional abuse and scores were rated on a two-point (yes/no) format.

Physical Abuse. Retrospective reports on physical abuse by parents or guardians was obtained utilizing single-items that describe different experiences of serious violent treatment (aged <12; please see Table 4). The items asked whether respondents had experienced seven different types of abuse and scores were rated on a two-point (yes/no) format.

Sexual Abuse. Retrospective reports on sexual abuse by parents or guardians were obtained utilizing single-items that describe experiences of serious sexual abuse (aged $<24$; please see Table 5). The four types of abuse were rated on a two-point (yes/no) format.

\section{RESULTS}

\section{Physical Neglect}

A total of $3.0 \%$ of the sample experienced some form of physical neglect from their parents or guardians under the age of 12 . When the sample was split by gender $2.6 \%$ of all males and $3.4 \%$ of all females reported experiencing physical neglect. The most prevalent experience reported was being responsible for their own care whilst sick (total $=5.9 \%$ ). The most prevalent experience reported by males $(6.2 \%)$ and females $(5.7 \%)$ remained consistent with that reported by the full sample. When the sample was split by child protection status a total of $2.1 \%$ of the non-protection cases and $16.0 \%$ of child protection cases reported experiencing some form of physical neglect at the hands of their parents or guardians. The most prevalent of which, for the nonprotection cases, was again being responsible for own care 
Table 1. Demographic Characteristics of Child Non-Protection Cases and Child Protection Cases

\begin{tabular}{|c|c|c|c|}
\hline & $\begin{array}{c}\text { Total Sample Weighted } \\
N=\mathbf{2 9 8 0} \text { (Percent Values) }\end{array}$ & $\begin{array}{l}\text { Child Non-Protection Case } \\
N=2128 \text { (Percent Values) }\end{array}$ & $\begin{array}{c}\text { Child Protection Case } \\
N=852 \text { (Percent Values) }\end{array}$ \\
\hline \multicolumn{4}{|l|}{ Gender } \\
\hline Male & 52.2 & 52.0 & 55.5 \\
\hline Female & 47.8 & 48.0 & 44.5 \\
\hline \multicolumn{4}{|l|}{ No. of Children } \\
\hline 0 & 91.2 & 91.8 & 81.6 \\
\hline 1 & 6.6 & 6.2 & 12.9 \\
\hline 2 & 1.8 & 1.6 & 4.8 \\
\hline$=>3$ & 0.3 & 0.3 & 0.6 \\
\hline \multicolumn{4}{|l|}{ Education } \\
\hline$<11 \mathrm{yrs}$ & 11.7 & 10.2 & 34.4 \\
\hline$>11 \mathrm{yrs}$ & 87.0 & 88.6 & 62.3 \\
\hline Still in education & 0.5 & 0.5 & 0.6 \\
\hline Other & 0.8 & 0.7 & 2.6 \\
\hline \multicolumn{4}{|l|}{ Marital Status } \\
\hline Married / Cohabiting & 46.0 & 46.1 & 44.7 \\
\hline Single & 54.0 & 53.9 & 55.2 \\
\hline
\end{tabular}

Note. All values are weighted.

Table 2. Experience of Physical Neglect from Parents or Guardians by Gender and Child Protection Status

\begin{tabular}{|c|c|c|c|c|c|}
\hline & Total & Male & Female & Child Non-Protection Case & Child Protection Case \\
\hline Aged $<12$ you were expected to wash own clothes (\%) & 2.9 & 1.7 & 4.2 & 2.4 & 10.8 \\
\hline $\begin{array}{l}\text { Aged }<12 \text { you had to attend school in dirty clothes because } \\
\text { there were no clean ones available (\%) }\end{array}$ & 1.5 & 1.6 & 1.4 & 1.1 & 8.0 \\
\hline $\begin{array}{l}\text { Aged }<12 \text { you were occasionally starved due to lack of food } \\
\text { or no one available to prepare meals (\%) }\end{array}$ & 1.2 & 1.0 & 1.4 & 0.7 & 8.8 \\
\hline Aged $<12$ you were responsible for own care when sick (\%) & 5.9 & 6.2 & 5.7 & 5.5 & 13.1 \\
\hline Aged $<12$ had to call a doctor for yourself when ill (\%) & 0.6 & 0.5 & 0.6 & 0.5 & 2.1 \\
\hline Total (\%) & 3.0 & 2.6 & 3.4 & 2.1 & 16.0 \\
\hline
\end{tabular}

Note: All percentage values are weighted; Total = Positive endorsement of at least two items; Categories were not mutually exclusive.

Table 3. Experience of Emotional Abuse from Parents or Guardians by Gender and Child Protection Status

\begin{tabular}{|l|c|c|c|c|c|}
\hline & Total & Male & Female & Child Non-Protection Case & Child Protection Case \\
\hline \hline Total $(N)$ & 2980 & 1579 & 1401 & 2128 & 852 \\
\hline Weighted $(N)$ & 2980 & 1555 & 1425 & 2794 & 186 \\
\hline $\begin{array}{l}\text { Addressed in humiliating (e.g. being called lazy, stupid, or } \\
\text { useless) manner by parents/guardians (\%) }\end{array}$ & 13.1 & 12.6 & 13.7 & 12.0 & 30.6 \\
\hline
\end{tabular}


Table 3. contd...

\begin{tabular}{|c|c|c|c|c|c|}
\hline & Total & Male & Female & Child Non-Protection Case & Child Protection Case \\
\hline Humiliated or degraded in public by parents/guardians (\%) & 5.4 & 4.4 & 6.4 & 4.7 & 16.4 \\
\hline $\begin{array}{l}\text { Threatened about getting thrown out of the home by par- } \\
\text { ents/guardians }(\%)\end{array}$ & 13.6 & 15.3 & 11.7 & 12.3 & 33.3 \\
\hline Threatened about violent punishment by parents/guardians (\%) & 3.0 & 3.1 & 2.9 & 2.4 & 12.0 \\
\hline $\begin{array}{l}\text { Parents/guardians have through their behaviour shown that you } \\
\text { were unwanted, unloved, and worthless (\%) }\end{array}$ & 4.9 & 4.1 & 5.8 & 3.9 & 19.8 \\
\hline Parents/guardians have critized or bullied you constantly (\%) & 2.9 & 2.0 & 3.9 & 2.3 & 12.3 \\
\hline Total $(\%)$ & 5.2 & 4.4 & 6.1 & 4.2 & 19.6 \\
\hline
\end{tabular}

Note. All percentage values are weighted; Total = Positive endorsement of at least three items; Categories were not mutually exclusive.

Table 4. Experience of Physical Abuse from Parents / Guardians by Sex and Child Protection Status

\begin{tabular}{|c|c|c|c|c|c|}
\hline & Total & Male & Female & Child Non-Protection Case & Child Protection Case \\
\hline Total $(N)$ & 2980 & 1579 & 1401 & 2128 & 852 \\
\hline Weighted $(N)$ & 2980 & 1555 & 1425 & 2794 & 186 \\
\hline Beaten with an object, such as a whip or coat hanger? $(\%)$ & 2.6 & 3.2 & 2.1 & 2.1 & 11.4 \\
\hline Threatened with a weapon, such as a knife or a gun? $(\%)$ & 0.4 & 0.4 & 0.5 & 0.3 & 2.5 \\
\hline Had objects thrown at you? $(\%)$ & 2.7 & 3.2 & 2.2 & 2.1 & 12.0 \\
\hline Grabbed round the neck and chocked? (\%) & 0.5 & 0.3 & 0.6 & 0.3 & 2.5 \\
\hline Been left with burn or bite marks? $(\%)$ & 0.2 & 0.1 & 0.3 & 0.1 & 1.9 \\
\hline $\begin{array}{l}\text { Had injuries such as broken bones, stab wounds, brain } \\
\text { haemorrhage, or burns which were treated by a doctor? (\%) }\end{array}$ & 0.3 & 0.2 & 0.4 & 0.2 & 2.2 \\
\hline $\begin{array}{l}\text { Been hit, kicked or exposed to violence which has resulted } \\
\text { in bruising, bleeding, or other physical injuries? }(\%)\end{array}$ & 2.2 & 2.3 & 2.2 & 1.6 & 12.0 \\
\hline Total $(\%)$ & 5.4 & 6.3 & 4.5 & 4.5 & 19.7 \\
\hline
\end{tabular}

Experience of physical abuse from parents / guardians by sex and child protection status

Note. All percentage values are weighted; Total = Positive endorsement of at least one item; Categories were not mutually exclusive.

Table 5. Experiences of Sexual Abuse by Sex and Child Protection Status

\begin{tabular}{|c|c|c|c|c|c|}
\hline & Total & Male & Female & Child Non-Protection Case & Child Protection Case \\
\hline Total $(N)$ & 2980 & 1579 & 1401 & 2128 & 852 \\
\hline Weighted $(N)$ & 2980 & 1555 & 1425 & 2794 & 186 \\
\hline $\begin{array}{l}\text { Experienced sexual touching or someone exposing their } \\
\text { private parts /sex organs to you }(\%)\end{array}$ & 2.6 & 0.5 & 4.8 & 2.1 & 9.5 \\
\hline Experienced attempted intercourse (\%) & 2.6 & 0.4 & 5.0 & 2.2 & 9.2 \\
\hline Experienced forced / completed intercourse (\%) & 1.9 & 0.2 & 3.8 & 1.6 & 6.5 \\
\hline Experienced other types of sexual behaviour (\%) & 0.8 & 0.2 & 1.4 & 0.6 & 3.8 \\
\hline Total $(\%)$ & 3.4 & 0.7 & 6.4 & 2.9 & 11.6 \\
\hline
\end{tabular}

Experiences of sexual abuse by sex and child protection status

Note. All percentage values are weighted; Total = Positive endorsement of at least one item; Categories were not mutually exclusive; Values pertain to experiences occurring under the age of 24 .

when sick $(5.5 \%)$. However, this differed for the child protection cases, the most prevalent experience reported was 'often had to care for yourself due to parental alcohol or drugs problems' $(19.0 \%)$. For further details of the seven physical neglect experiences please see Table 2. 


\section{Emotional Abuse}

A total of $5.2 \%$ of the sample experienced some form of emotional abuse from their parents or guardians under the age of 12 . When the sample was split by gender $4.4 \%$ of all males and $6.1 \%$ of all females reported experiencing emotional abuse. When the sample was split by child protection status a total of $4.2 \%$ of non child protection cases reported experiencing some form of emotional abuse at the hands of their parents or guardians. Of those individuals highlighted as a child protection case a total of $19.6 \%$ reported experiencing some form of emotional abuse. The most prevalent of emotional abuse experiences across all categories was being threatened about getting thrown out of the home by parents or guardians $($ Total $=13.6 \%$; Males $=15.3 \%$; Females $=$ $11.7 \%$; Child non-protection case $=12.3 \%$; Child protection case $=33.3 \%$ ). For further details of the six emotional abuse experiences please see Table 3 .

\section{Physical Abuse}

A total of $5.4 \%$ of the sample experienced some form of physical abuse from their parents or guardians under the age of 12 . When the sample was split by gender $6.3 \%$ of all males and $4.5 \%$ of all females reported experiencing physical abuse. The most prevalent experience reported was having an object throw at them $(2.7 \%)$ and being hit with an object, such as a whip or coat hanger $(2.6 \%)$. The most prevalent experience reported by males remained consistent with that reported by the full sample (having an object throw at them and being hit with an object; both $3.2 \%$ ). The most prevalent experiences reported by females was having objects thrown at them $(2.2 \%)$ and being hit, kicked, or exposed to violence resulting in injury (2.2\%). When the sample was split by child protection status a total of $4.5 \%$ of non child protection cases reported experiencing some form of physical abuse at the hands of their parents or guardians. The most prevalent of which was again consistent with that reported by the full sample and by males (having an object throw at them and being hit with an object; both $2.1 \%$ ). Of those individuals highlighted as a child protection case a total of $19.7 \%$ reported experiencing some form of physical abuse. The most prevalent of which was having an object thrown at them $(12.0 \%)$. For further details of the seven physical abuse experiences please see Table 4.

\section{Childhood Sexual Abuse}

Four questions enquired about types of childhood sexual abuse experiences occurring under the age of 24 . In total, $3.4 \%$ of the sample $($ Males $=0.7 \%$ \& Females $=6.4 \%$; Nonchild protection $=2.9 \% \&$ Child protection $=11.6 \%$ ) experienced sexual abuse under the age of 24. In the total sample, the most prevalent experiences reported were having experienced sexual touching or someone exposing their private parts or sex organs and attempted intercourse (both 2.6\%). When split by gender the most prevalent experience for males was having sexual touching or someone exposing their private parts or sex organs $(0.5 \%)$. For females the most prevalent experience was attempted intercourse (5.0\%). When split by child protection status the most prevalent experience for non child protection cases was attempted intercourse $(2.2 \%)$. For child protection cases the most prevalent experience was having sexual touching or someone exposing their private parts or sex organs $(9.5 \%)$. For further details of the specific types of sexual abuse across gender and child protection status please see Table $\mathbf{5}$.

\section{DISCUSSION}

The current study aimed to conduct a detailed assessment of the prevalence of childhood maltreatment in Denmark while also assessing whether childhood abuse varies as a function of gender or child protection status. Participants were asked questions regarding specific experiences of four types of maltreatment; physical neglect, emotional abuse, physical abuse and sexual abuse. In total, $3.0 \%$ of the sample experienced physical neglect, $5.2 \%$ experienced emotional abuse, $5.4 \%$ experienced physical abuse, and $3.4 \%$ experienced sexual abuse from parents or guardians. It is notable that much of the preceding literature in relation to childhood abuse has focused on childhood sexual abuse [10]. However, in addition to sexual abuse, a UK based prevalence study conducted by May-Chahal and Cawson [10] also addressed the prevalence of physical abuse, neglect, and emotional abuse. They concluded that the prevalence of serious physical abuse was $7 \%$, compared to the $5.4 \%$ prevalence of physical abuse in the current study. These estimates lie centrally to the range of estimates reported from both UK (15\%) [17] and US (2.3\%) [18] studies in relation to levels of severe physical violence against children. In relation to the prevalence of neglect, the May-Chahal and Cawson [10] study reported a UK prevalence of $6 \%$ compared to the Danish prevalence of $3.0 \%$. With regards to the prevalence of emotional abuse, the UK prevalence was reported at $6 \%$ compared to the Danish prevalence of $5.2 \%$. The specific items in relation to neglect and emotional abuse are similar across both the current study and the May-Cahal \& Cawson [10] study. This is notable given that May-Chahal and Cawson [10] stated that "There have been no prevalence studies using a comprehensive set of behavioural items to measure emotional abuse or neglect and no two studies measure the same items." (p. 981).

With regards to sexual abuse, the May-Cahal and Cawson [10] UK study reported a total prevalence of $10 \%$ compared to the total prevalence of $3.4 \%$ reported for the current study. However, it is important to note that there are vast differences between these two studies in relation to the items which pertain to the experiences of sexual abuse. For example, the May-Cahal and Cawson [10] study assessed sexual abuse under the age of 16 in relation to whether or not such was contact or non-contact sexual abuse and in relation to who was the perpetrator of the abuse (i.e., parent/carer; other relative; other known people; or stranger/person just met). The current study asked a number of questions pertaining to specific types of sexual abuse experiences (cf. Table 5). Interestingly, the May-Cahal and Cawson [10] study reported that when asked about the experiences of contact sexual abuse under the age of 16, by parents or carers, the reported prevalence was $1 \%$. The prevalence of non-contact sexual abuse was less than $1 \%$. Notably, albeit that the sexual abuse experiences questions were asked in relation to events occurring under the age of 24 , the current study also asked one direct, yet broad question in relation to the experience of sexual abuse under the age of 13 . This question, thus experience of sexual abuse under the age of 13 was endorsed by 
$1 \%$ of the total sample. More recently, Elklit and Petersen [7] conducted a study assessing the prevalence of 19 traumatic experiences in adolescents aged 14 and 15 years across four countries; Denmark $(N=390)$, Iceland $(N=206)$, Lithuania $(N=183)$, and the Faeroe Islands $(N=687)$. The total sample consisted of 1466 students. Three of the 19 experiences were sexual abuse, physical abuse, and severe childhood neglect. Results concluded that although these events were among the least prevalent of the traumatic experiences, physical abuse was experienced by $5 \%$ of the sample, sexual abuse was experienced by $4 \%$ of the sample, and severe childhood neglect was experienced by $4 \%$ of the sample. When broken down by individual countries, the prevalence of these traumas for Denmark alone was reported as: physical abuse 3.6\%, severe childhood neglect $3.1 \%$, and sexual abuse $1.5 \%$. The current results report higher rates of physical abuse $(5.4 \%)$ and sexual abuse $(3.4 \%)$ in Denmark but similar rates for neglect $(3.0 \%)$. However, as noted in the introduction, methodological and sample age variations can significantly alter the reported prevalence rates and thus hinder comparison between studies, even when the population of interest belongs to the same country.

\section{GENDER}

Gender differences in the prevalence of childhood sexual abuse has been of particular interest to researchers. Indeed, studies of sexual abuse by gender have been conducted in the UK and the US. A UK based study estimated that $5 \%$ of girls compared to $2 \%$ of boys experienced sexual abuse which included penetration or coerced masturbation [19]. Notably, US based studies report higher prevalence rates of sexual abuse compared to the UK prevalence rates. Indeed, two meta-analytic studies have been conducted. The first concluded that the prevalence of sexual abuse as experienced by females ranged from $12-17 \%$ as compared to the $5-8 \%$ of males experiencing sexual abuse [20]. The second concluded that the prevalence of sexual abuse as experienced by females ranged from $8-30 \%$ as compared to the $2-16 \%$ of males experiencing sexual abuse. Finkelhor [13] conducted a review in which he reported that non US studies estimate that approximately $20 \%$ of females compared to $10 \%$ of males experience sexual abuse. Elklit and Petersen [7] reported that sexual abuse had been experienced by $1.3 \%$ of females compared to $0.25 \%$ of male Danish adolescents. The current study, using more specified behavioural items, reported a higher prevalence of sexual abuse in both females $(6.4 \%)$ and males $(0.7 \%)$. However, it is important to note that sexual abuse often goes unreported particularly with regard to male victims. Indeed, a review regarding the sexual abuse of male children and adolescents reported that there is a high level of secrecy surrounding the sexual abuse of boys [21].

The current study concluded that a higher percentage of females reported experiencing all types of abuse with the exception of physical abuse. Indeed, these results support those of previous studies. For example, MacMillan et al. [22] examined the Ontario Health Survey and concluded that physical abuse was reported more often by males compared to females. Likewise, May-Chahal and Cawson [10] reported more males compared to females had experienced 'violent treatment from anyone' or 'serious physical abuse from a parent / carer'. With regards to emotional abuse and physical neglect, the May-Chahal and Cawson [10] study supported the current findings as they also reported that females more often report emotional abuse and physical neglect (defined as absence of physical care) than males.

\section{Child Protection Status}

The current study revealed that a higher percentage of children defined as a child protection case (i.e., a case where the council, according to the files of local social workers, had provided support for the child and the family or had organised the childs placement with a foster family due to concerns about the well-being and the development of the child), reported experiencing all four types of childhood abuse compared to those not defined as a child protection case. However, it is important to note that these cases may have been referred for support because of the experience of childhood maltreatment and have not necessarily experienced maltreatment as a function of being in care. However, this finding is not particularly surprising given that children and adolescents who are in care are often regarded as those individuals in society who are the most vulnerable [23]. Notably, however a child protection case within the current study is not necessarily a child who is placed in care away from the home. This highlights issues with the definition of a child protection case, further highlighting issues with making comparisons between studies.

\section{Strengths and Limitations}

The current study is a nationally representative study of 24 year olds in Denmark. Furthermore, the current study enquires about specific abuse experiences rather than simply enquiring whether or not an individual experienced a broadly defined type of abuse. Moreover, we surveyed the individuals who potentially experienced the abuse rather than surveying parents about whether or not they perpetrated abuse. The current study is however not without limitation. First, the study achieved a response rate of $63 \%$. Generally, this is regarded as typical for population survey data; nevertheless it raises questions in relation to how those who participated differed from those who choose not to participate. In particular, it is possible that those who choose not to participate were more likely to have experienced maltreatment. Ultimately, this may result in a reduction of the true rate of maltreatment within the Danish population. This is however, a relatively common and often hard to avoid methodological limitation of many studies attempting to assess the true prevalence of childhood maltreatment. Second, the physical neglect, emotional abuse, and physical abuse items were asked in relation to specific experiences which occurred under the age of 12 , whereas the sexual abuse items were asked in relation to experiences which occurred under the age of 24. Although this potentially inflated the prevalence of sexual abuse experiences, we did enquire about sexual abuse aged 12 or under, using a single direct question. This resulted in a prevalence of sexual abuse of $1 \%$. We can speculate that the higher prevalence of sexual abuse is related to the additional time-frame however we must also consider that the literature on sexual abuse reports that estimates of prevalence based on Yes/No reports of any sexual abuse experience, often results in underestimates of prevalence compared to an approach that enquires about specific sexual 
abuse experiences. Additionally, the current questioning format focused on experiences which occurred at the hands of parents or guardians. Thus, ignores potential abuse which may have been perpetrated by other family members or acquaintances. This may be particularly relevant for sexual abuse given that we queried about experiences up to the age of 24 rather than under the age of 12 as with other abuse types (Fergusson et al., 1996). Both of these points may dilute the true prevalence of abuse and thus may also hinder comparisons with alternative studies. However, difficulties in comparing with other studies are a widely acknowledged limitation within this field (as previously discussed) and not solely a limitation of the current study.

\section{Conclusion and Implications for Future Research}

In conclusion, childhood abuse is prevalent within society. However, there are a number of methodological difficulties with hinder the revelation of true prevalence rates. Studies, such as the current, help to highlight not only the estimated prevalence but help to highlight that several methodological issues need to be considered in future research. For example, future research would profit from employing standardised definitions of abuse. In addition, research in this area should primarily be conducted using representative samples employing standardised methodological procedures. By doing so, researchers would be able to make comparisons between studies and across countries and thus gain a clearer picture of the true prevalence of childhood abuse. One further consideration relates to the fact that abuse types rarely occur in a stand-alone fashion. Indeed, there may be considerable overlap between abuse experiences, in other words, children who are physically abused may also experience emotional abuse. Thus, future research, and a future line of enquiry for the current researchers, may attempt to uncover whether or not homogeneous groups of abuse victims exist.

\section{CONFLICT OF INTEREST}

The authors confirm that this article content has no conflicts of interest.

\section{ACKNOWLEDGEMENTS}

We thank the Danish National Research Foundation for generous research support.

\section{REFERENCES}

[1] Cromer K, Sachs-Ericsson N. The Association between Childhood Abuse and the Occurrence of Adult Health Problems: Moderation via Current Life Stress. J Trauma Stress 2006; 6: 967-711.

[2] Sachs-Ericsson N, Cromer K, Hernandez A, et al. A review of child abuse, health, and pain-related problems: The role of psychi- atric disorders and current life stress. J Trauma Dissociation 2009; 10: $170-88$.

[3] Sedlak A, Gragg F, Mettenburg J, et al. Fourth National Incidence Study of Child Abuse and Neglect (NIS-4) 2008. Available from: https://www.nis4.org/DOCS/Nis4Design_Method_Summary.pdf

[4] Ronan KR, Canoy DF, Burke KJ. Child maltreatment: Prevalence, risk, solutions, obstacles. Aust Psychol 2010; 44: 195-213.

[5] Fallon B, Trocmé N, Fluke J, et al. Methodological challenges in measuring child maltreatment. Child Abuse Negl 2010; 34: 70-9.

[6] Desai S, Arias I, Thompson MP, et al. Childhood victimization and subsequent adult revictimization assessed in a nationally representative sample of women and men. Violence Victims 2002; 17: 63953.

[7] Elklit A, Petersen T. Exposure to traumatic events among adolescents in four nations. Torture 2008; 18: 2-11.

[8] Fergusson DM, Boden JM, Horwood LJ. Exposure to childhood sexual and physical abuse and adjustment in early childhood. Child Abuse Negl 2008; 32: 607-19.

[9] Helweg-Larsen K, Larsen HB. Unges trivsel år. En undersøgelse med fokus på seksuelle overgreb i barndommen. København: Statens Institut for Folkesundhed; 2002.

[10] May-Chahal C, Cawson P. Measuring child maltreatment in the United Kingdom: A study of the prevalence of child abuse and neglect. Child Abuse Negl 2005; 29: 969-84.

[11] Scher CD, Forde DR, McQuaid JR, et al. Prevalence and demographic correlates of childhood maltreatment in an adult community sample. Child Abuse Negl 2004; 28: 167-80.

[12] Zielinski DS. Child maltreatment and adult socioeconomic wellbeing. Child Abuse Negl 2009; 33: 666-7

[13] Finkelhor D. The international epidemiology of child sexual abuse. Child Abuse Negl 1994; 18: 409-17.

[14] Willis GB, Gonzales A. Methodological Issues in the Use of Survey Questionnaires to Assess the Health Effects of Torture. J Nerv Ment Dis 1998; 186: 293-89.

[15] Banyard VL, Williams LM, Siegel, JA. The Long-Term Mental Health Consequences of Child Sexual Abuse: An Exploratory Study of the Impact of Multiple Traumas in a Sample of Women. J Trauma Stress 2001; 14: 697-715

[16] Ullman SE, Filipas HH. Gender differences in social reactions to abuse disclosures, post-abuse coping, and PTSD of child sexual abuse survivors. Child Abuse Negl 2005; 29: 767-82

[17] Smith M, Bee P, Heverin A, Nobes G. Parental control within the family: The nature and extent of parental violence to children. In: Department of Health, Ed. Child protection. Messages from research. London: HMSO, 1995; pp. 83-5

[18] Straus M A, Gelles R J. Societal change in family violence from 1975 to 1985 as revealed by two national surveys. J Marriage Fam 1986; 48: 465-79

[19] Kelly L, Regan L, Burton S. An exploratory study of the prevalence of sexual abuse in a sample of 16-21 year olds. London: University of North London 1991.

[20] Goery KM, Leslie DR. The Prevalence of Child Sexual Abuse: Integrative Review Adjustment for Potential Response and Measurement Biases. Child Abuse Negl 1997; 21: 391-8.

[21] Watkins B, Bentovim A. The sexual abuse of male children and adolescents: a review of current research. J Clin Psychol Psychiatry 1992; 33: 197-248.

[22] MacMillan HL, Fleming JE, Trocme N, et al. Prevalence of Child Physical and Sexual Abuse in the Community; Results from the Ontario Health Supplement. J Am Med Assoc 1997; 278: 131-5

[23] Kendrick A, Steckly L, Lerpiniere K. Ethical issues, research and vulnerability: gaining the views of children and young people in residential care. Child Geogr 2008; 6: 79-3.

Received: July 22, 2013

(C) Christoffersen et al.; Licensee Bentham Open.

This is an open access article licensed under the terms of the Creative Commons Attribution Non-Commercial License (http://creativecommons.org/licenses/by-nc/3.0/) which permits unrestricted, non-commercial use, distribution and reproduction in any medium, provided the work is properly cited. 